\title{
LncRNA-NEF is involved the regulation of gastric carcinoma cell proliferation by targeting RUNX1
}

\author{
XUE WANG $^{1}$, XUE JIANG $^{2}$, LI ZHOU $^{1}$, ZHUO WANG $^{1}$, HE HUANG $^{1}$ and MENGQIAO WANG ${ }^{1}$ \\ ${ }^{1}$ Department of General Surgery, Chengdu Fifth People's Hospital, Chengdu, Sichuan 611130; \\ ${ }^{2}$ Department of Dermatology, Chongqing First People's Hospital, Chongqing 400011, P.R. China
}

Received March 23, 2018; Accepted October 26, 2018

DOI: $10.3892 / \mathrm{mmr} .2019 .9869$

\begin{abstract}
Neighboring enhancer of FOXA2 (NEF) is a newly discovered long non-coding RNA (IncRNA) that serves an oncogenic function in the metastasis of hepatocellular carcinoma, while its involvement in other types of cancer and in tumor cell proliferation remain unknown. In the present study, tumor tissues and adjacent healthy tissues were obtained from patients with gastric carcinoma, and blood was extracted from patients with gastric carcinoma and healthy controls. Expression of NEF in those tissues was detected using a reverse transcription-quantitative polymerase chain reaction. Receiver operating characteristic curve analysis was performed to evaluate the diagnostic value of serum lncRNA NEF for gastric carcinoma. All patients were followed-up for 5 years following discharge, and survival curves were plotted to evaluate the diagnostic value of serum IncRNA-NEF for gastric carcinoma. LncRNA-NEF overexpression and small interfering RNA (siRNA) silencing cell lines were established and the effects on cell proliferation and runt-related transcription factor 1 (Runx1) expression were detected using a Cell Counting Kit-8 assay and western blot analysis, respectively. It was revealed that NEF was significantly downregulated in tumor tissues compared with in adjacent tissues. Levels of circulation NEF in serum were lower in patients with gastric carcinoma compared with in healthy controls, and were decreased with the increasing stages of primary tumor. Serum NEF is a sensitive diagnostic and prognostic marker for gastric carcinoma. NEF siRNA silencing promoted, and overexpression inhibited, gastric carcinoma proliferation. In addition, NEF overexpression promoted, and NEF siRNA silencing inhibited, Runx1 expression. Therefore, it was concluded that
\end{abstract}

Correspondence to: Dr Mengqiao Wang, Department of General Surgery, Chengdu Fifth People's Hospital, 33 Mashi Street, Wenjiang, Chengdu, Sichuan 611130, P.R. China

E-mail: nakmdm74e5hcd4@163.com

Key words: gastric carcinoma, long non-coding RNA-neighboring enhancer of FOXA2, runt-related transcription factor 1, downregulation, proliferation
lncRNA NEF may participate in the regulation of cancer cell proliferation by regulating Runx1 expression.

\section{Introduction}

In spite of the progress made in the treatment and prevention of human cancer types, gastric carcinoma (as a type of malignancy that develops from the inner layer of the stomach tissue) remains the third most common cause of cancer-associated mortality worldwide $(1,2)$. The wide application of chemotherapy, radiation treatment and other targeted treatments has substantially improved the survival of patients with gastric carcinoma during last several decades. However, surgical resection remains the only radical treatment for patients with gastric carcinoma who are at an early stage of the cancer (3). At present, there is no radical treatment for patients with gastric carcinoma at advance stages. However, as the majority of patients with gastric carcinoma are diagnosed at advance stages, particularly in developing countries, including China (4), survival of those patients remains poor.

Long non-coding RNAs (lncRNAs) are a group of non-coding RNA composed of $>200$ nucleotides (5). It has been reported that lncRNAs are involved in nearly every aspect of almost all critical physiological processes and pathological changes in the human body (6). Neighboring enhancer of FOXA2 (NEF) is a newly discovered lncRNA known to possess functionality only in the metastasis of hepatocellular carcinoma (7). In the present study, the involvement of lncRNA-NEF in gastric carcinoma was examined and the clinical potentials discussed.

\section{Patients and methods}

Subjects. A total of 98 patients with gastric carcinoma who were diagnosed by pathological examination and treated at the Chengdu Fifth People's Hospital (Sichuan, China) between January 2011 and January 2013 were selected as the patient group. The patient group included 60 men and 38 women, and the age ranged from 22 to 71 years, with a mean age of $45.7 \pm 8.2$ years. Patients with other severe diseases, other gastric diseases or mental disorders were not included. Staging of primary tumor types were performed according to the following criteria: Tis, carcinoma in situ, 13 cases; T1, tumor invades muscularis mucosae, lamina propria, or submucosa, 
15 cases; T2, tumor invades muscularis propria, 19 cases; T3, tumor penetrates subserosal connective tissue but no invasion of visceral peritoneum or adjacent structures was found, 20 cases; T4, tumor invades serosa (visceral peritoneum) or its adjacent structures, 31 cases. At the same time, 32 healthy people were included to serve as the control group. Control group included 20 men and 12 women, and the age ranged from 21 to 71 years, with a mean age of $45.9 \pm 8.8$ years. No notable differences in age and sex were identified between the patient group and control group. The present study was ethically approved by Ethics Committee of Chengdu Fifth People's Hospital. All patients provided written informed consent.

Specimen collections. Tumor tissues and adjacent healthy tissues within $5 \mathrm{~cm}$ of the tumor were collected from 45 patients during surgical operation. The tissues were confirmed to be tumor or healthy tissues by pathological examinations. Blood (about $15 \mathrm{ml}$ ) was also extracted from elbow vein of all participants. Blood was maintained at room temperature for $2 \mathrm{~h}$, followed by centrifugation at $1,000 \mathrm{x} \mathrm{g}$ at room temperature for $20 \mathrm{~min}$ to collect serum. All specimens were stored in liquid nitrogen prior to use.

Cell lines and cell culture. Human gastric cell line SNU-1 (Asian) and Hs 746T (Caucasian) were purchased from American Type Culture Collection (Manassas, VA, USA). Cells were cultured with ATCC-formulated RPMI-1640 Medium containing $10 \%$ fetal bovine serum at $37^{\circ} \mathrm{C}$ in a $5 \% \mathrm{CO}_{2}$ incubator. Cells were harvested during the logarithmic growth phase for subsequent experiments.

Construction of IncRNA-NEF silencing and overexpression cell lines. LncRNA-NEF small interfering RNA (siRNA; 5'-GGAGCUGUUUGGGCAAUAATT-3') and non-specific silencing control (negative control) were provided by Shanghai GenePharma Co., Ltd. (Shanghai, China). NEF cDNA was inserted into a pIRSE2-EGFP vector (Clontech Laboratories, Inc., Mountainview, CA, USA) to establish a NEF expression vector. Cells of two cell lines (SNU-1 and Hs 746T) were cultured overnight to reach $80-90 \%$ confluence, and Lipofectamine 2000 reagent (cat no. 11668-019; Invitrogen; Thermo Fisher Scientific, Inc., Waltham, MA, USA) was then used to transfect $10 \mathrm{nM}$ vector or $50 \mathrm{nM}$ siRNA (negative control) into $5 \times 10^{5}$ cells in each well of a 6 -well plate at $37^{\circ} \mathrm{C}$ in a $5 \% \mathrm{CO}_{2}$ incubator. Cells were incubated with transfection reagents, and vectors or siRNAs for $6 \mathrm{~h}$, followed by washing with fresh cell culture medium to avoid cytotoxicity.

Cell proliferation assay. Cells of both SNU-1 and Hs 746T cell lines were collected during the logarithmic growth phase to produce cell suspensions $\left(4 \times 10^{4}\right.$ cell $\left./ \mathrm{ml}\right)$. Then, a $100 \mu \mathrm{l}$ cell suspension containing $4 \times 10^{3}$ cells was added into each well of a 96-well plate. Cells were cultured in an incubator $\left(37^{\circ} \mathrm{C}\right.$ and $\left.5 \% \mathrm{CO}_{2}\right)$ and Cell Counting Kit-8 (CCK-8) solution (10 $\left.\mu \mathrm{l}\right)$ was added into each well and incubated for 24, 48, 72 and $96 \mathrm{~h}$. Following incubation at $37^{\circ} \mathrm{C}$ for an additional $4 \mathrm{~h}$, the optical density value at $450 \mathrm{~nm}$ was measured using the Fisherbrand ${ }^{\mathrm{TM}}$ accuSkan $^{\mathrm{TM}}$ GO UV/Vis Microplate Spectrophotometer (Thermo Fisher Scientific, Inc.).
Reverse transcription-quantitative polymerase chain reaction (RT-qPCR). Tumor tissues and adjacent healthy tissues were ground in liquid nitrogen, followed by the addition of TRIzol reagent (Invitrogen; Thermo Fisher Scientific, Inc.) to extract total RNA. In vitro cultured cells of both SNU-1 and Hs 746T cell lines were directly mixed with TRIzol reagent (Invitrogen; Thermo Fisher Scientific, Inc.) at room temperature to extract total RNA. Reverse transcription was then performed to synthesize cDNA, followed by the preparation of PCR reactions using $\mathrm{SYBR}^{\circledR}$-Green Real-Time PCR Master Mixes (Thermo Fisher Scientific, Inc.) and the following primers: 1ncRNA-NEF forward, 5'-CTGCCGTCT TAAACCAACCC-3' and reverse, 5'-GCCCAAACAGCT CCTCAATT-3'; human $\beta$-actin forward, 5'-GACCTCTAT GCCAACACAGT-3' and reverse, 5'-AGTACTTGCGCT CAGGAGGA-3'. PCR reaction conditions were as follows: $95^{\circ} \mathrm{C}$ for $40 \mathrm{sec}$, followed by 40 cycles of $15 \mathrm{sec}$ at $95^{\circ} \mathrm{C}$ and $30 \mathrm{sec}$ at $55^{\circ} \mathrm{C}$. Cq values were produced using the $2^{-\Delta \Delta \mathrm{Cq}}$ method (8). Relative expression levels of lncRNA-NEF were normalized to the endogenous control ( $\beta$-actin).

Western blot analysis. Total protein extraction was performed using RIPA solution (Thermo Fisher Scientific, Inc.) on ice with $30 \mathrm{~min}$ incubation, and protein quantification was performed using the BCA method. Subsequently, 10\% SDS-PAGE gel electrophoresis was performed using $30 \mu \mathrm{g}$ protein per lane, followed by gel transfer to polyvinylidene fluoride (PVDF) membranes. PVDF membranes were incubated with $5 \%$ skimmed milk for $1.5 \mathrm{~h}$ at room temperature, followed by incubation with rabbit anti-human primary antibodies against Runx1 (1:2,000; cat no. ab15309; Abcam, Cambridge, UK) and GAPDH (1:1,000; cat no. ab8245; Abcam) overnight at $4^{\circ} \mathrm{C}$. Subsequently, membranes were incubated with anti-rabbit immunoglobulin $\mathrm{G}$ horseradish peroxidase-conjugated secondary antibody (1:1,000; cat no. MBS435036; MyBioSource, Inc., San Diego, CA, USA) at room temperature for $1.5 \mathrm{~h}$, followed by signal development using ECL reagents (Sigma-Aldrich; Merck KGaA, Darmstadt, Germany). Signals were scanned using the MYECL ${ }^{\text {TM }}$ Imager (Thermo Fisher Scientific, Inc.), and the relative expression level of Runx1 was normalized to the endogenous control GAPDH using Image J version 1.46 software (National Institutes of Health, Bethesda, MD, USA).

Statistical analysis. SPSS19.0 (SPSS, Inc., Chicago, IL, USA) was used in the present study for all statistical analyses. Measurement data were represented as mean \pm standard deviation. Comparisons of measurement data between two groups and among multiple groups were performed using a paired Student's t-test and one-way analysis of variance followed by a least-significant-difference post-hoc test, respectively. Continuous data were compared using a $\chi^{2}$ test. Receiver operating characteristic (ROC) curve analysis was performed to evaluate the diagnostic values of serum circulating lncRNA-NEF for gastric carcinoma. According to the median relative serum level of circulating lncRNA-NEF (5.02), all patients were divided into a high expression group and a low expression group. Survival data were collected during a 5 year follow-up and the Kaplan-Meier method was used to plot survival curves. Survival curves were compared using a log 


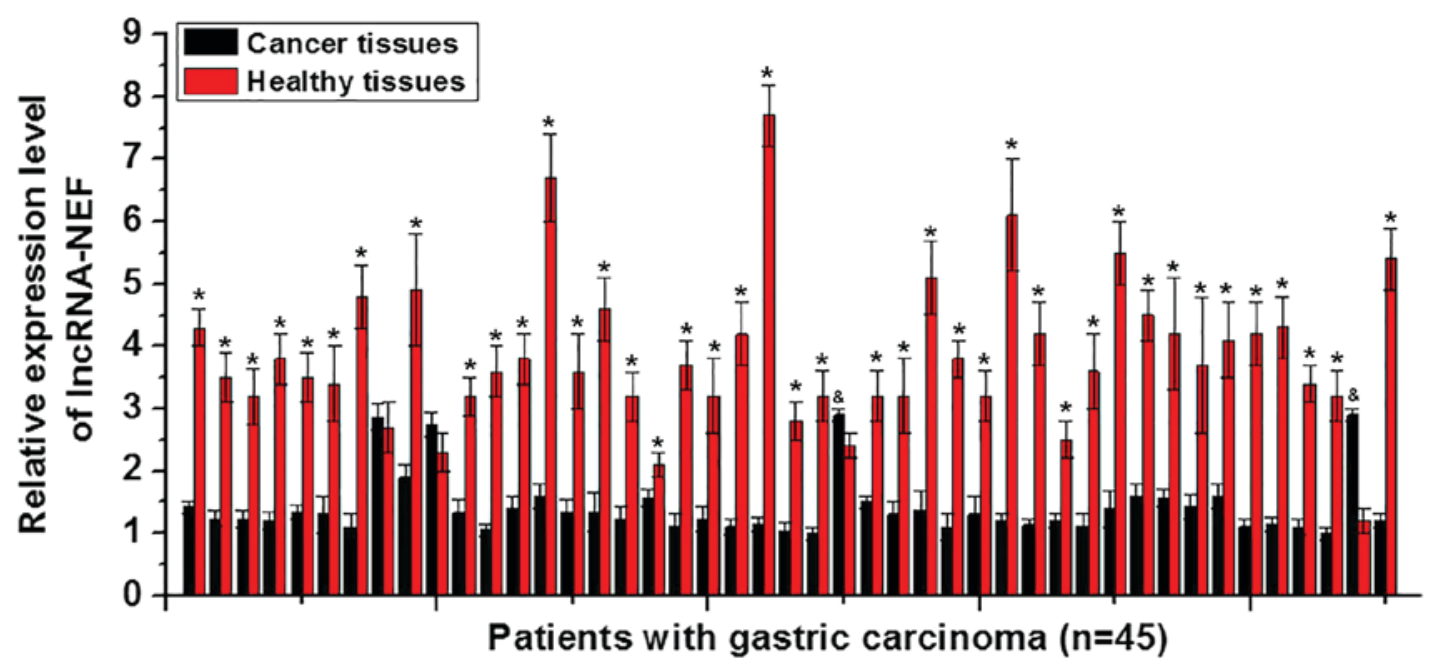

Figure 1. Expression of lncRNA-NEF in cancer tissues and adjacent healthy tissues of 45 patients with gastric carcinoma. A significantly higher expression level of IncRNA-NEF in adjacent healthy tissues compared with cancer tissues was identified in the majority of patients with gastric carcinoma. ${ }^{*}<0.05$ vs. cancer tissues; ${ }^{\text {P }}<0.05$ vs. healthy tissues. LncRNA, long non-coding RNA; NEF, neighboring enhancer of FOXA2.

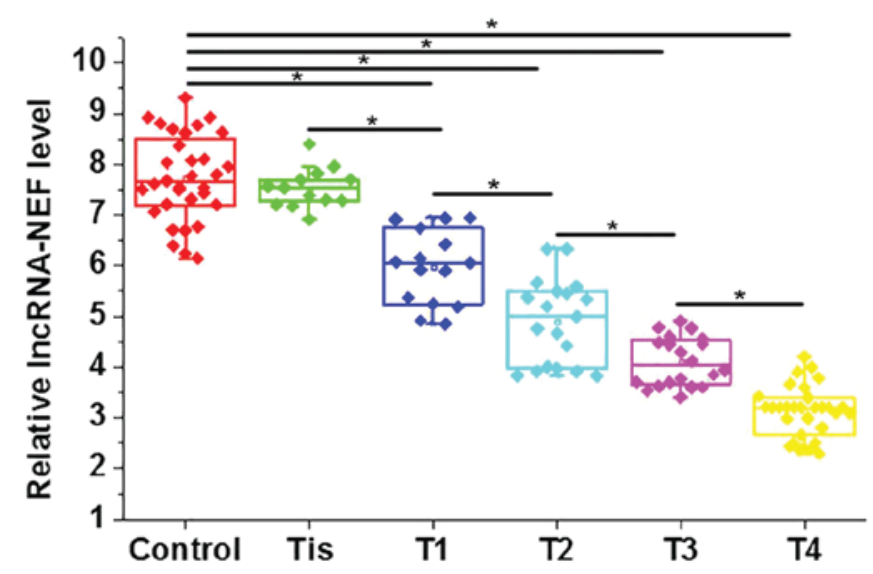

Figure 2. Serum levels of 1ncRNA-NEF in the control group and patient group. Levels of circulating lncRNA-NEF decreased gradually with the increase of primary tumor stage. ${ }^{*} \mathrm{P}<0.05$ with comparisons shown by lines. LncRNA, long non-coding RNA; NEF, neighboring enhancer of FOXA2.

rank t-test. $\mathrm{P}<0.05$ was considered to indicate a statistically significant difference.

\section{Results}

Expression of lncRNA-NEF in cancer tissues and adjacent healthy tissues. The differential expression of a gene in tumor tissues and healthy tissues indicate its involvement in the tumor. In the present study, tumor tissues and adjacent healthy tissues were collected from 45 patients with gastric carcinoma, and the expression levels of IncRNA-NEF in those tissues were measured using RT-qPCR. Among those 45 patients, 41 were revealed to exhibit a significantly higher expression level of lncRNA-NEF in the adjacent healthy tissues compared with the cancer tissues, accounting for $91.1 \%$ of all patients $(\mathrm{P}<0.05$; Fig. 1). In contrast, a significantly lower expression level of lncRNA-NEF in adjacent healthy tissues compared with cancer tissues was only identified in 2 cases, accounting for $4.4 \%$ of all patients $(\mathrm{P}<0.05)$. No significant difference was identified in the remaining 2 cases, accounting for $4.4 \%$ (Fig. 1). The present data indicates that the downregulation of lncRNA-NEF is likely to be involved in gastric carcinoma.

Expression of IncRNA-NEF in patients with gastric carcinoma at different stages of a primary tumor. To further confirm the involvement of IncRNA-NEF in gastric carcinoma, serum levels of lncRNA-NEF in patients with gastric carcinoma and healthy controls were also measured using RT-qPCR. Results revealed that levels of circulating lncRNA-NEF in the serum were significantly higher in the control group compared with patients with different stages of gastric carcinoma except stage Tis $(\mathrm{P}<0.05$; Fig. 2). In addition, the level of circulating lncRNA-NEF significantly decreased gradually with the increase of primary tumor stage $(\mathrm{P}<0.05$; Fig. 2$)$.

Diagnostic and prognostic value of serum circulating lncRNA-NEF for gastric carcinoma. Differential expression of a gene may possess diagnostic potential for disease diagnosis. Therefore, receiver operating characteristic curve analysis was performed to evaluate the diagnostic values of serum circulating lncRNA-NEF for gastric carcinoma. The area under the curve was 0.9349 with $95 \%$ confidence intervals of 0.8958 to $0.9741 \quad(\mathrm{P}<0.0001$, compared with the line of identity; Fig. 3A). According to the median serum level of circulating lncRNA-NEF (5.02), all patients were divided into a high expression group and a low expression group. Survival data were collected during a 5 year follow-up and the Kaplan-Meier method was used to plot survival curves. Survival curves were compared using a log rank t-test. Comparison of survival curves revealed that the overall survival rate of patients with a high serum level of ncRNA-NEF was significantly higher compared with that of patients with a low serum level of lncRNA-NEF $(\mathrm{P}<0.01$; Fig. 3B). The present data suggests that serum circulating lncRNA-NEF has substantial diagnostic and prognostic value for gastric carcinoma.

Effects of lncRNA-NEF overexpression and knockdown on gastric carcinoma cell proliferation. LncRNA-NEF 

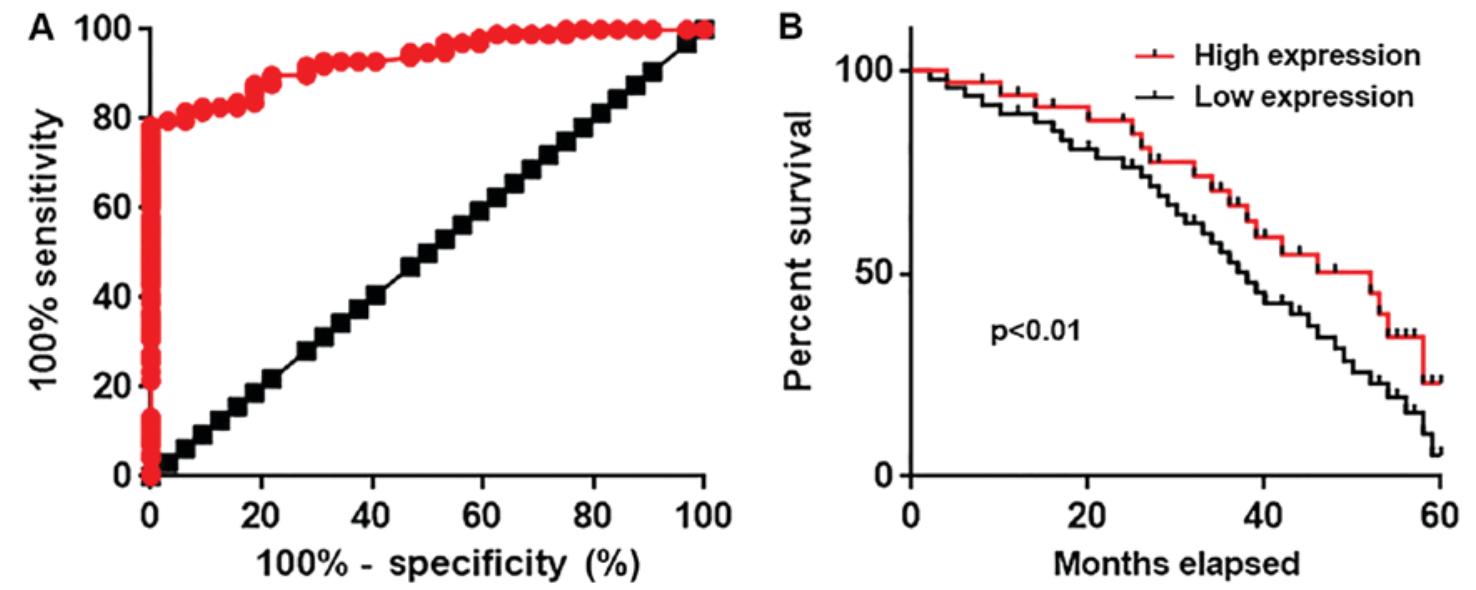

Figure 3. Diagnostic and prognostic value of serum circulating lncRNA-NEF for gastric carcinoma. (A) Diagnostic values of serum circulating lncRNA-NEF analyzed using receiver operating characteristic curve analysis. (B) Survival curves of patients with high and low serum levels of lncRNA-NEF. Serum circulating IncRNA-NEF may serve as a diagnostic and prognostic biomarker for gastric carcinoma. LncRNA, long non-coding RNA; NEF, neighboring enhancer of FOXA2.
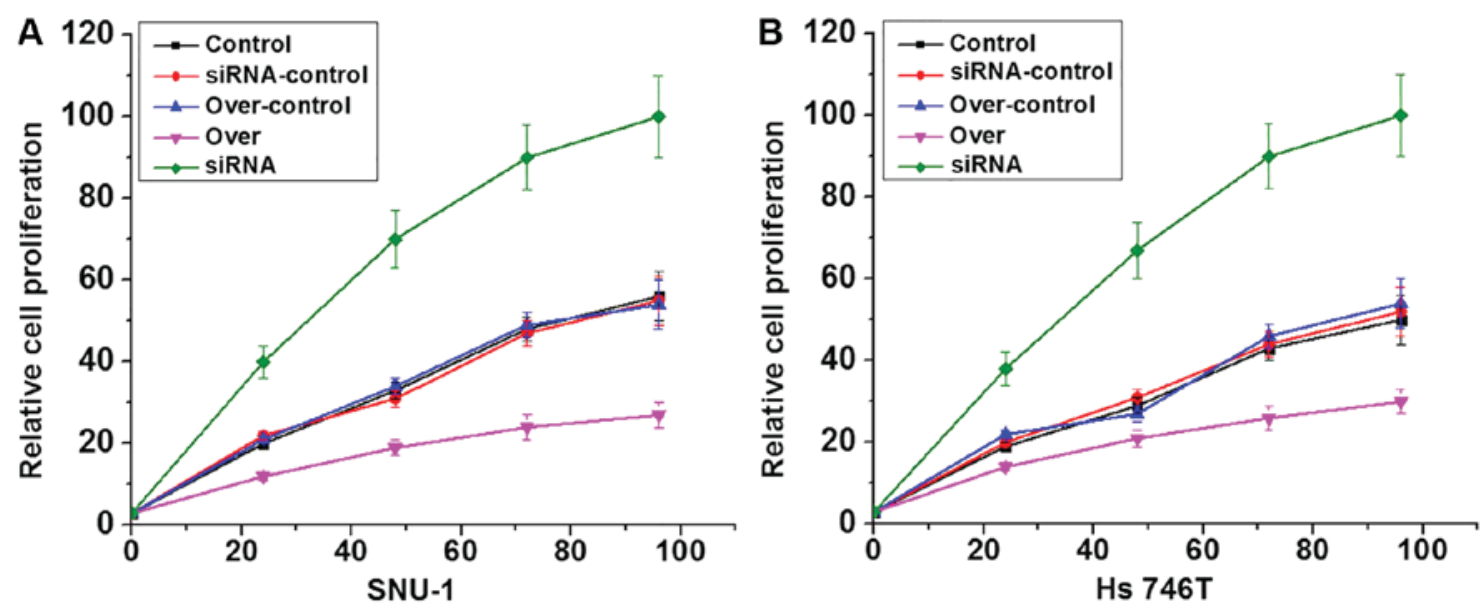

Figure 4. Effects of lncRNA-NEF overexpression and knockdown on gastric carcinoma cell proliferation. LncRNA-NEF overexpression significantly inhibited the proliferation of, while siRNA silencing significantly promoted the proliferation of, (A) SNU-1 and (B) Hs 746T gastric carcinoma cell lines. LncRNA, long non-coding RNA; NEF, neighboring enhancer of FOXA2; siRNA, small interfering RNA.

overexpression and siRNA silencing gastric carcinoma cell lines were constructed and confirmed by measuring the expression level of lncRNA-NEF through RT-qPCR (data not shown). Effects of lncRNA-NEF overexpression on cell proliferation were investigated using a CCK-8 assay. As presented in Fig. 4, IncRNA-NEF overexpression clearly inhibited the proliferation of the cells of two gastric carcinoma cell lines compared with the control cells, whilst siRNA silencing notably promoted proliferation compared with the control cells, confirming the inhibitory effects of lncRNA-NEF on gastric carcinoma cell proliferation.

Effects of IncRNA-NEF knockdown and overexpression on Runxl expression. Runx1 is a key player in the regulation of tumor growth in different types of cancers including gastric carcinoma (9). Therefore, the effects of lncRNA-NEF knockdown and overexpression on Runx1 expression were investigated using western blot analysis. As presented in Fig. 5A, lncRNA-NEF knockdown significantly inhibited the expression levels of Runx1 in two gastric carcinoma cell lines compared with the control cells $(\mathrm{P}<0.05)$. In contrast,
lncRNA-NEF overexpression significantly promoted the expression levels of Runx1 in the two gastric carcinoma cell lines compared with the controls ( $\mathrm{P}<0.05$; Fig. 5B).

\section{Discussion}

The onset, development and progression of gastric carcinoma are accompanied with changes in the expression patterns of a large set of IncRNAs. In a previous study, Cao et al (10) identified 88 differentially expressed lncRNAs in gastric carcinoma. LncRNA H19 was revealed to be upregulated in cancer tissues compared with adjacent healthy tissues around the tumor in the majority of patients with gastric carcinoma, which supports its function as an oncogenic gene in the pathogenesis of this disease (11). In contrast, maternally expressed 3 (which functions as a tumor suppressor gene) is downregulated in gastric carcinoma (12). In addition to altered expression patterns during the development and progression of gastric carcinoma, a number of lncRNAs, including urothelial cancer associated 1, also demonstrated an altered expression pattern during the application of chemotherapy, 

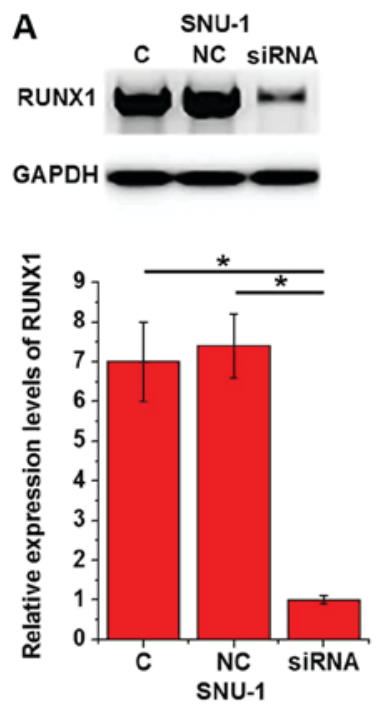
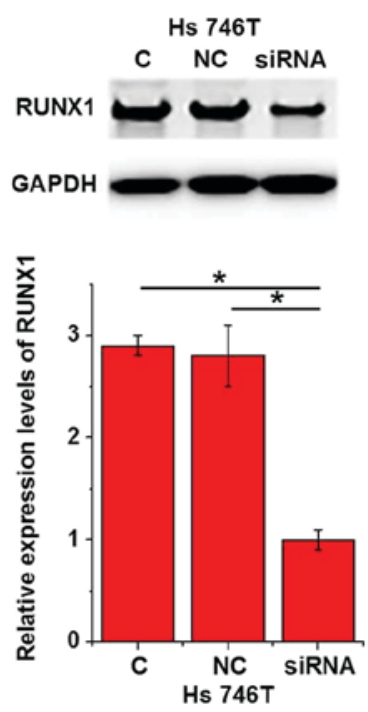
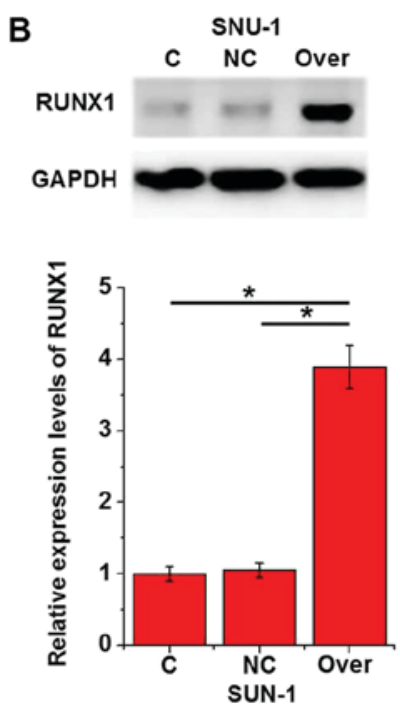
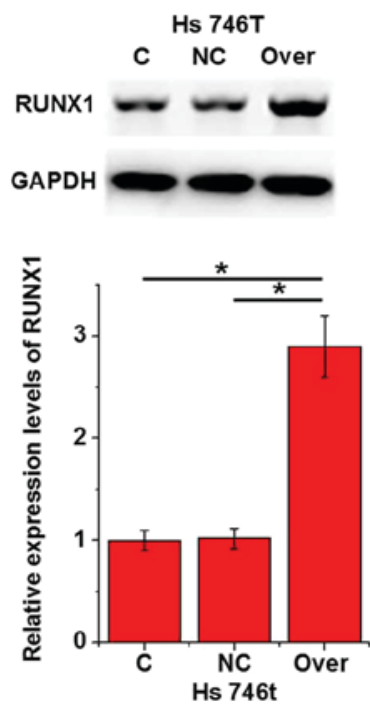

Figure 5. Effects of lncRNA-NEF knockdown and overexpression on Runx1 expression. This figure shows the effects of lncRNA-NEF knockdown. (A) and overexpression (B) on RUNX1 expression. lncRNA-NEF knockdown significantly inhibited, while lncRNA-NEF overexpression significantly promoted the expression of RUNX1 in cells of two gastric carcinoma cell lines. * $\mathrm{P}<0.05$ with comparisons shown by lines. LncRNA, long non-coding RNA; NEF, neighboring enhancer of FOXA2; siRNA, small interfering RNA; Runx1, C, control (cells treated with Lipofectamine 2000 reagent only); NC, negative control (cells transfected with empty vectors or negative control siRNA).

which in turn affects treatment outcomes (13). LncRNA-NEF is a newly discovered IncRNA with downregulated expression in hepatocellular carcinoma (7). In the present study, significantly reduced expression levels of LncRNA-NEF were identified in the majority of patients with gastric carcinoma compared with healthy controls. In addition, reduced serum levels of circulating lncRNA-NEF were also observed in patients with gastric carcinoma compared with healthy controls, and serum lncRNA-NEF levels gradually decreased with the increase of primary tumor stages. These data suggest that the downregulation of lncRNA-NEF is involved in the pathogenesis of gastric carcinoma.

In spite of the progression made in the development of treatment strategies, treatment of gastric carcinoma remains challenging due to the low early diagnosis rate (14). Therefore, identifying how to improve the diagnosis of gastric carcinoma at an early stage is a major task for treatment. Circulating lncRNAs have been proven to be sensitive biomarkers for the identification of certain pathological processes including the development and progression of gastric carcinoma. For instance, the abnormally upregulated expression of lncRNA H19 has been proven to effectively distinguish patients with gastric carcinoma from healthy controls (15). In the present study, lncRNA-NEF was proven to be a sensitive diagnostic marker for gastric carcinoma. Accurate prediction of prognosis is also critical for the survival of patients with malignancies $(16,17)$. In the present study, high levels of serum circulating IncRNA-NEF were proven to be associated with poorer survival conditions of patients with gastric carcinoma. These data suggest that serum circulating lncRNA-NEF may serve as a promising diagnostic and prognostic biomarker for gastric carcinoma. However, it is worth mentioning that lncRNA-NEF is a newly discovered lncRNA with unknown expression patterns in other diseases. Therefore, multiple markers should be combined to improve the diagnosis.

A previous study has demonstrated that lncRNA-NEF is involved in the metastasis, but not growth, of hepatocellular carcinoma (7). In the present study, IncRNA-NEF was revealed to exert inhibitory effects on the proliferation of gastric carcinoma cells, indicating the different pathogenesis of those two types of malignancies. Runx 1 is a transcription factor that participates in different human malignancies by regulating cell proliferation $(18,19)$. LncRNA H19, as a oncogenic lncRNA, promotes the proliferation of gastric carcinoma cells by inhibiting the expression of Runx1 $(9,20)$. In the present study, NEF overexpression promoted, and NEF siRNA silencing inhibited, Runx1 expression in SNU-1 (Asian) and Hs 746T (Caucasian) cell lines, each originating from different ethnic backgrounds. These data suggest that lncRNA-NEF inhibited the proliferation of gastric carcinoma cells by inhibiting the expression of Runx1, and the function of IncRNA-NEF was unlikely to be affected by different ethnic backgrounds, which has been proven to influence factors in other types of malignancies (21).

In conclusion, NEF was significantly downregulated in gastric carcinoma. Serum NEF may serve as a sensitive diagnostic and prognostic marker for gastric carcinoma. NEF overexpression promoted, and NEF siRNA silencing inhibited, gastric carcinoma cell proliferation. Additionally, NEF overexpression promoted, and NEF siRNA silencing inhibited, Runx1 expression. Therefore, it was concluded that lncRNA NEF participates in the regulation of cancer cell proliferation by regulating Runx 1 expression. However, the present study remains challenged by the small sample size. Further studies with a bigger sample size are required in order to further confirm the conclusions.

\section{Acknowledgements}

Not applicable.

\section{Funding}

No funding was received. 


\section{Availability of data and materials}

The datasets used during the present study are available from the corresponding author upon reasonable request.

\section{Authors' contributions}

XW and MW conceived and designed the study. XW, XJ, LZ, $\mathrm{ZW}$ and $\mathrm{HH}$ performed the experiments. MW wrote the paper. $\mathrm{XW}, \mathrm{XJ}, \mathrm{LZ}, \mathrm{ZW}$ and $\mathrm{HH}$ reviewed and edited the manuscript. All authors read and approved the manuscript and agree to be accountable for all aspects of the research in ensuring that the accuracy or integrity of any part of the work are appropriately investigated and resolved.

\section{Ethics approval and consent to participate}

All experimental protocols were approved by the Institutional Review Board of Chengdu Fifth People's Hospital.

\section{Patient consent for publication}

Not applicable.

\section{Competing interests}

The authors state that they have no competing interests.

\section{References}

1. Roder DM: The epidemiology of gastric cancer. Gastric Cancer 5: $5-11,2002$

2. Plummer M, Franceschi S and Muñoz N: Epidemiology of gastric cancer. IARC Sci Publ 157: 311-326, 2004.

3. Orditura M, Galizia G, Sforza V, Gambardella V, Fabozzi A, Laterza MM, Andreozzi F, Ventriglia J, Savastano B, Mabilia A, et al: Treatment of gastric cancer. World J Gastroenterol 20: 1635-1649, 2014.

4. Chen W, Zheng R, Baade PD, Zhang S, Zeng H, Bray F, Jemal A, Yu XQ and He J: Cancer statistics in China, 2015. CA Cancer J Clin 66: 115-132, 2016.

5. Perkel JM: 'Visiting noncodarnia'. Biotechniques 54: 303-304, 2013.

6. Esteller M: Non-coding RNAs in human disease. Nat Rev Gen 12: 861-874, 2011.

7. Liang WC, Ren JL, Wong CW, Chan SO, Waye MM, Fu WM and Zhang JF: LncRNA-NEF antagonized epithelial to mesenchymal transition and cancer metastasis via cis-regulating FOXA2 and inactivating Wnt// $\beta$-catenin signaling. Oncogene 37: 1445-1456, 2018.
8. Livak KJ and Schmittgen TD: Analysis of relative gene expression data using real-time quantitative PCR and the 2(-Delta Delta C(T)) method. Methods 25: 402-408, 2001.

9. Liu G, Xiang T, Wu QF and Wang WX: Long noncoding RNA H19-derived miR-675 enhances proliferation and invasion via RUNX1 in gastric cancer cells. Oncol Res 23: 99-107, 2016.

10. Cao WJ, Wu HL, He BS, Zhang YS and Zhang ZY: Analysis of long non-coding RNA expression profiles in gastric cancer. World J Gastroenterol 19: 3658-3664, 2013.

11. Li H, Yu B, Li J, Su L, Yan M, Zhu Z and Liu B: Overexpression of 1ncRNA H19 enhances carcinogenesis and metastasis of gastric cancer. Oncotarget 5: 2318-2329, 2014.

12. Sun M, Xia R, Jin F, Xu T, Liu Z, De W and Liu X: Downregulated long noncoding RNA MEG3 is associated with poor prognosis and promotes cell proliferation in gastric cancer. Tumor Bio 35: 1065-1073, 2014.

13. Shang C, Guo Y, Zhang J and Huang B: Silence of long noncoding RNA UCA1 inhibits malignant proliferation and chemotherapy resistance to adriamycin in gastric cancer. Cancer Chemother Pharm 77: 1061-1067, 2016.

14. Smyth EC, Verheij M, Allum W, Cunningham D, Cervantes A and Arnold D; ESMO Guidelines Committee: Gastric cancer: ESMO clinical practice guidelines for diagnosis, treatment and follow-up. Annal Onco 27 (Suppl 5): v38-v49, 2016.

15. Zhou X, Yin C, Dang Y, Ye F and Zhang G: Identification of the long non-coding RNA H19 in plasma as a novel biomarker for diagnosis of gastric cancer. Sci Reports 5: 11516, 2015.

16. Rugge M, Fassan M and Graham DY: Epidemiology of gastric cancer. In: Gastric Cancer. Strong V (ed). Springer, Cham, pp23-32, 2015.

17. Cristescu R, Lee J, Nebozhyn M, Kim KM, Ting JC, Wong SS, Liu J, Yue YG, Wang J, Yu K, et al: Molecular analysis of gastric cancer identifies subtypes associated with distinct clinical outcomes. Nat Med 21: 449-456, 2015.

18. Keita M, Bachvarova M, Morin C, Plante M, Gregoire J, Renaud MC, Sebastianelli A, Trinh XB and Bachvarov D: The RUNX1 transcription factor is expressed in serous epithelial ovarian carcinoma and contributes to cell proliferation, migration and invasion. Cell Cyc 12: 972-986, 2013.

19. Hong D, Andrew J, Fritz KF, Fitzgerald MP, Stein JL, Lian J and Stein G: Runx1 possesses anti-tumor activity and inhibits stemness in breast cancer cells. Cancer Res 77 (Suppl 13): S5534-S5542, 2017.

20. Zhuang M, Gao W, Xu J, Wang P and Shu Y: The long non-coding RNA H19-derived miR-675 modulates human gastric cancer cell proliferation by targeting tumor suppressor RUNX1. Biochem Biophys Res Commun 448: 315-322, 2014.

21. Hoffmann TJ, Van Den Eeden SK, Sakoda LC, Jorgenson E, Habel LA, Graff RE, Passarelli MN, Cario CL, Emami NC, Chao CR, et al: A large multiethnic genome-wide association study of prostate cancer identifies novel risk variants and substantial ethnic differences. Cancer Discov 5: 878-891, 2015.

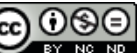

This work is licensed under a Creative Commons Attribution-NonCommercial-NoDerivatives 4.0 International (CC BY-NC-ND 4.0) License. 